Асланян Наталья Павловна

доктор юридических наук, профессор, профессор кафедры международного права Северо-Кавказского филиала Российского государственного университета правосудия

\section{К ВОПРОСУ О КЛАССИФИКАЦИИ ОХРАНИТЕЛЬНЫХ ГРАЖДАНСКИХ ПРАВООТНОШЕНИЙ}

Аннотация:

Под классификацией в науке понимается либо процесс классифицирования некоторых объектов, либо результат такого процесса. И процесс классифицирования, и полученная в результате классификация как его конечный продукт между собой тесно связаны, поскольку результат классифицирования напрямую зависит от качества проведения данной исследовательской процедуры. В настоящей статье автор предпринимает попытку рассмотреть оба аспекта вопроса применительно к классифицированию охранительных гражданских правоотношений. Анализируются предложенные на сегодняшний день в иивилистической литературе классифи кации таких правоотношений, отстачвается тезис о необходимости их естественной классификации. Кроме того, обосновывается вывод, что нацеленность на количественные показатели в классификационной работе ведет к кризису перепроизводства сведений об изучаемом объекте, что тормозит развитие научного знания.

Ключевые слова:

классификация, естественная классификация, искусственная классификация, охранительные гражданские правоотношения, сущность охранительных гражданских правоотношений, классификация охранительных гражданских правоотношений.
Aslanyan Nataliya Pavlovna

LLD, Professor International Law Department, North Caucasus branch of Russian State University of Justice

\section{CONCERNING THE CLASSIFICATION OF PROTECTIVE CIVIL LEGAL RELATIONS}

\begin{abstract}
Summary:
Classification is considered by science as either the process of classifying several objects or the result of this process. The process of classification and the resultant classification as its final product are closely related, since the result of classification is directly dependent on the quality of this research procedure. The author attempts to examine both aspects of the issue as applied to the classification of protective civil legal relations. The paper analyzes the classifications of this legal relationship offered by civil jurisprudence at the present date; the necessity of their natural classification is advanced. It is concluded that the quantity-oriented approach to the classification leads to overproduction of information on the subject matter which impedes the development of scientific knowledge.
\end{abstract}

Keywords: classification, natural classification, artificial classification, protective civil legal relations, essence of protective civil legal relations, classification of protective legal relations.

В науке классификации приписывается высокий статус в силу способности решать многие задачи (упорядочивать объекты исследования, способствовать построению теории и т. д.) [1, с. 62-73]. Однако главной научной задачей классификации признается ее способность служить средством выявления сущности объектов познания [2, с. 346]. Как указывается в специальной литературе, «научное и прикладное значение классификаций столь велико, что нынешнее наше неумение управлять классифицированием - организовывать этот процесс так, чтобы получались классификации, заведомо удовлетворительные в исполнении заданных функций, - воспринимается как причина многих актуальных проблем нашего времени» [3, с. 4].

В правоведении научная классификация характеризуется как тонкий инструмент проникновения в сущность предмета и признается ее высокая роль в познавательном процессе [4, с. 30]. Классификация является специфическим способом организации научного знания [5, р. 238]. Будучи качественно выполненной, она способна внести значительный вклад в познание изучаемого объекта, а также, обладая большой эвристической силой, определить дальнейшие пути его развития $[6$, с. $67 ; 7$, с. 128$]$.

Между тем проведение грамотной классификации - далеко не простая задача, а неумелое классифицирование ведет к кризису перепроизводства сведений, т. е. к такой ситуации, когда сведений об объекте много, а «те научные и практические задачи, для решения которых эти сведения добывались, с их помощью решить не удается» [8, с. 4]. Говоря иначе, проведение классификации ради классификации является непродуктивным, не достигает целей, стоящих перед научной классификацией, и вместо пользы приносит вред, поскольку ведет к увеличению массива малозначимой информации об изучаемом объекте.

В цивилистической литературе теория классификации практически не разрабатывается, однако цивилистам (как, впрочем, и представителям других областей правоведения) присуща 
высокая классификационная активность. Вопрос о классификации тех или иных объектов поднимается едва ли не в каждой работе гражданско-правового характера, особенно если учесть, что, пользуясь правилами формальной логики, осуществлять классификацию несложно и эта операция в самом ее примитивном виде доступна любому студенту [9].

Как известно, классификация является частным случаем деления. А разделить можно всегда и все, хотя вряд ли любое разделение можно назвать научной классификацией. В этом отношении весьма показателен пример А.А. Ивина, который со ссылкой на Х.Л. Борхеса приводит отрывок из «некоей китайской энциклопедии», классифицирующей животных на: «а) принадлежащих императору; б) бальзамированных; в) прирученных; г) молочных поросят; д) сирен; е) сказочных; ж) бродячих собак; з) заключенных в настоящую классификацию; и) буйствующих как в безумии; к) неисчислимых; л) нарисованных очень тонкой кисточкой из верблюжьей шерсти; м) прочих; н) только что разбивших кувшин; о) издалека кажущихся мухами» [10, с. 139].

Классификации могут быть различными. В связи с этим большое значение имеет указание на то, что классификация может производиться либо по существенным признакам (основаниям), либо по несущественным. В первом случае она носит название естественной классификации, во втором - искусственной, прикладной, вспомогательной. «Естественная классификация - классификация по важным, существенным для рассматриваемого объекта признакам, - пишет А.А. Ивин. - Искусственная классификация - классификация, опирающаяся на второстепенные, случайные признаки» [11, с. 42]. По утверждению Б.М. Кедрова, искусственная классификация толкует связи между вещами и знаниями о них «не как связи, сложившиеся необходимым образом в процессе... развития, но как связи случайные, внешние, а нередко и устанавливаемые самим человеком ради удобства охвата... материала. Напротив, подлинно естественная классификация в той или иной форме отражает именно те связи и отношения между подлежащими классификации объектами, которые сложились в итоге их исторического развития или развития знаний о них» $[12$, с. 6].

Разграничивая естественную и искусственную классификации, следует учитывать, что первая «отражает происхождение вещей, т. е. является генетической» [13, с. 118]. «Истинно научная классификация должна быть естественной» - со времен К. Линнея ученые отстаивают эту идею [14, с. 94]. Между тем в правоведении сложилось стойкое представление, что классификация проводится с целью более детально и с разных сторон взглянуть на исследуемый объект [15, с. 37], «подчеркнуть различные стороны изучаемого явления» [16, с. 42-43], увидеть его новые аспекты и грани [17, с. 15]. Полагаем, что классификация, сводящаяся к механическому делению (членению) предметов и явлений, хотя и дает возможность выявить какие-то их признаки, сама по себе научной ценности не имеет, поскольку основной задачи научной классификации - постижения сущности объектов познания - не достигает.

Хорошей иллюстрацией к изложенному является сложившееся на сегодняшний день положение дел с классификацией охранительных гражданских правоотношений. Насколько нам удалось установить, по данному вопросу в доктрине сформировались три позиции, представленные в трудах Е.Я. Мотовиловкера, А.В. Милькова и Д.Н. Кархалева. Можно было бы упомянуть также воззрения Е.Я. Крашенинникова и А.В. Власовой, однако данные ученые непосредственно на классификации охранительных гражданских правоотношений не останавливаются, а классифицируют охранительные гражданские права, поэтому в настоящей работе мы мнение данных авторов не рассматриваем, отсылая читателя к их работам [18].

Справедливо указывая, что охранительные правоотношения, впрочем, как и любые другие, можно разделять на группы по разным признакам (например, по отраслям права, юридическим фрактам или субъектам), Е.Я. Мотовиловкер подчеркивает, что имеется «сущностный критерий классификации, без выделения которого теория охранительных правоотношений была бы неполной. Это основное разделение вытекает из самой природы охранительных правоотношений, диктуется логикой их рождения» [19, с. 25]. Таким сущностным критерием этот автор признает содержание охранительного правоотношения, а точнее - право управомоченного лица. Согласно данному критерию исследователь разделяет все охранительные правоотношения на две группы: 1) те, в которых управомоченный имеет «возможность прибегнуть к способности юрисдикционного органа применить власть»; 2) те, в которых управомоченный имеет «возможность действовать самому» [20, с. 26]. Субъективное право в правоотношениях первого вида есть право на иск (притязание), дающее управомоченному возможность требовать от юрисдикционного органа принудительного осуществления своего требования к обязанному лицу [21, с. 53-60, 74-80, 96; 22, с. 26-27]. Субъективное право в правоотношениях второго вида есть право на односторонние действия [23, с. 125].

А.В. Мильков также избирает критерием классификации охранительных гражданских правоотношений их содержание, но при этом учитывает не только возможность управомоченного лица либо прибегнуть к помощи юрисдикционного органа, либо действовать самостоятельно, но и особенности прав на односторонние действия, проявляющиеся в характере применяемого принуждения. Поэтому исследователь делит охранительные гражданские правоотношения не на две группы, а на три: 1) исковые правоотношения, т. е. те, в которых охранительное субъективное 
гражданское право на иск обладает способностью к принудительному осуществлению юрисдикционным органом; 2) секундарные правоотношения, т. е. те, в которых охранительное секундарное право обладает способностью к принудительному осуществлению путем совершения односторонних юридических действий управомоченным лицом; 3) правоотношения по самозащите, т. е. те, в которых охранительное субъективное право на самозащиту обладает способностью к принудительному осуществлению путем совершения односторонних фактических действий управомоченным лицом [24, с. 11, 294-297, 325, 347-348, 371-372, 379-381].

Таким образом, в двух рассмотренных классификациях авторы в качестве критерия избирают существенный признак, т. е. проводят естественную классификацию, позволяющую четко разграничивать охранительные гражданские правоотношения и при этом не загромождающую предметное поле массивом бесполезной информации (что немаловажно).

Иным путем идет Д.Н. Кархалев [25, с. 43-48], который, как было отмечено, видит значение проводимой им классификации в том, чтобы подчеркнуть различные стороны изучаемого явления. Вероятно, поэтому он приводит 20 (!) самых разнообразных классификаций, в которых делит охранительные гражданские правоотношения: 1) по видам нарушенных субъективных прав на правоотношения, возникающие при нарушении авторских прав, жилищных прав, наследственных прав, вещных или обязательственных прав [26]; 2) «по основанию применения» на возникающие при наличии нарушения субъективного права и при наличии угрозы нарушения такого права [27]; 3) в зависимости от того, «имущественным или неимущественным способом исполняется охранительное обязательство», на имущественные и неимущественные охранительные правоотношения [28]; 4) по мерам принуждения на восстановительные (по реализации мер защиты), штрафные (по осуществлению мер ответственности), оперативные (по реализации мер оперативного воздействия), пресекательные (по реализации мер самозащиты) [29]; 5) в зависимости от характера нарушенного права на охранительные правоотношения, возникшие при нарушении имущественного права либо неимущественного права [30]; 6) в зависимости от того, «в денежной или в натуральной фрорме осуществляется восстановление нарушенного права (правового положения)», на такие, в которых правовое положение восстанавливается в денежной форме, и такие, в которых субъективное право восстанавливается в натуральной форме [31]; 7) по способу восстановления нарушенного права на те, в которых право восстанавливается в добровольном порядке, и те, в которых право восстанавливается в принудительном порядке [32]; 8) по критерию достижения цели на те, в которых цель достигнута (при надлежащем исполнении), и те, в которых цель может быть не достигнута [33]; 9) по соотношению «субъектов правоотношения и субъектов его исполнения» на те, в которых «субъекты правоотношения совпадают с субъектами восстановления права», и те, в которых «субъекты правоотношения не совпадают с субъектами исполнения охранительной обязанности» [34]; 10) «по количеству участников правоотношения на одной стороне (или на обеих сторонах)» на а) «охранительные правовые связи, в которых на управомоченной и обязанной стороне имеется только одно лицо», б) «охранительные правовые связи со множественностью лиц на одной или обеих сторонах обязательства (активная, пассивная, смешанная)»; 11) «по типу и результату противоправного поведения» на те, в которых одно противоправное действие повлекло нарушение одного субъективного права; те, в которых одно противоправное действие повлекло нарушение двух и более субъективных прав; те, в которых два или более противоправных действия повлекли нарушение одного права; 12) «по структуре действия по восстановлению нарушенного права» на «правоотношения с простой структурой действия по восстановлению права (достаточно одного действия для восстановления права)» и «правоотношения со сложной структурой действия по восстановлению права (требуется совершение нескольких действий по восстановлению права)»; 13) по связи охранительного правоотношения с договорным обязательством на те, которые возникают на основе договорных отношений, не прекращающихся при их нарушении; те, которые возникают в связи с прекращением нарушенного договорного обязательства; и те, которые возникают независимо от наличия или нарушения договорных обязательств [35]; 14) «по субъекту, осуществляющему гражданско-правовое принуждение» на те, в которых принуждение осуществляется в судебном порядке, и те, в которых оно осуществляется во внесудебном порядке самим потерпевшим [36]; 15) по возможности перемены лиц на те, в которых перемена лиц возможна, и те, в которых она запрещена законом; 16) «по объекту субъективного права на защиту» на те, в которых объектом являются материальные блага, и те, в которых объектом выступают нематериальные блага; 17) «по типу нарушенного гражданского правоотношения» на те, которые возникают при нарушении регулятивного правоотношения, и те, которые возникают при нарушении охранительного правоотношения; 18) по соотношению «основания возникновения правоотношения и основания применяемой меры принуждения» на те, в которых эти основания совпадают, и те, в которых они не совпадают; 19) по основаниям прекращения на а) «правоотношения, которые прекращаются по всем указанным в гл. 26 ГК РФ основаниям», б) «охранительные правоотношения, которые прекращаются по некоторым основаниям, предусмотренным в 
указанной главе Кодекса»; 20) «по распределению объема охранительной обязанности» на долевые, солидарные и субсидиарные.

В.Л. Кожара указывает: «В сознании большинства ученых глубоко и прочно коренится постулат: качество классификаций есть функция количества и качества знаний о классифицируемой действительности и способностей классификаторов» [37, с. 14]. Оставляя в стороне последний признак качественного классифицирования, заметим, что предложенные Д.Н. Кархалевым классификации существенно увеличивают массив информации об охранительных гражданских правоотношениях, качества знаний о них не повышают, но стойко ассоциируются с упомянутой «некоей китайской энциклопедией».

Классификация охранительных гражданских правоотношений имеет научное значение только тогда, когда позволяет раскрыть их сущность. Сущностным признаком охранительного гражданского правоотношения является способность охранительного субъективного гражданского права к принудительной реализации. Поскольку охранительные гражданские правоотношения неоднородны по этой способности (в одних случаях такая способность реализуется путем принуждения, применяемого юрисдикционным органом, а в других - применяемого самим управомоченным лицом), то их классификацию следует проводить именно в зависимости от специфики субъективного охранительного гражданского права. У Д.Н. Кархалева данная классификация затерялась под № 14, причем в искаженном виде.

Обобщая, отметим, что почти все «авторские» классификации Д.Н. Кархалева либо являются констатацией широко известных положений, либо ошибочны, либо надуманны. Для их всеобъемлющей критики понадобился бы солидный монографический труд. Такой цели мы перед собой не ставили, поскольку при написании настоящей статьи нами двигало стремление показать, что беспечный подход, нацеленный на количественные показатели в классификационной работе, ведет к кризису перепроизводства сведений об изучаемом объекте, что тормозит развитие науки. Из этого следует, что классификационная проблема, которая активно обсуждается в иных областях научного знания [38], стоит и перед гражданско-правовой наукой.

\section{Ссылки и примечания:}

1. Розова С.С. Классификационная проблема в современной науке. Новосибирск, 1986. 223 с.

2. Покровский М.П. О функциях классификации // Ежегодник-2012 : труды ИГГ УрО РАН. Вып. 160. Екатеринбург, 2013. C. $344-352$

3. Кожара В.Л. Классификационное движение. Борок, 2006. 40 с.

4. Исаков В.Б. Фактический состав в механизме правового регулирования. Саратов, 1980. 128 с.

5. Corbin A. Jural Relations and Their Classification [Электронный ресурс] // Faculty Scholarship Series. 1921. Paper 2873. URL: http://digitalcommons.law.yale.edu/cgi/viewcontent.cgi?article=3877\&context=fss papers (дата обращения: 05.12.2017)

6. Мейен С.В., Шрейдер Ю.А. Методологические аспекты теории классификации // Вопросы философии. 1976. № 12. C. 67-79.

7. Кожара В.Л. Феномен естественной классификации // Новые идеи в научной классификации : сборник научных трудов. Вып. 5. Екатеринбург, 2008. С. 117-143.

8. Кожара В.Л. Классификационное движение. С. 4

9. Как замечает Т. Чеховская, «способность членить окружающий мир ведь не прерогатива систематиков, а особенность человеческого мышления». См.: Чеховская Т. «Без которой - хаос» // Книги, открывающие мир. М., 1984. С. 93.

10. Ивин А.А. Логика : учебное пособие. М., 2008. 336 с.

11. Там же. С. 42.

12. Кедров Б.М. Классификация наук. В 3 кн. Кн. І. М., 1961. 472 с.

13. Кожара В.Л. Феномен ... С. 118.

14. Чеховская Т. Указ. соч. С. 94.

15. Орехов И.В. Проблемы классификации субинститутов права // Право. Журнал Высшей школы экономики. 2016 . № 1. C. $37-47$.

16. Кархалев Д.Н. Охранительное гражданское правоотношение. М., 2009. 332 с.

17. Иванов А.А. О проблеме классификации юридической ответственности (на примере ответственности в сфере охраны окружающей среды) // Вестник Волжского университета им. В.Н. Татищева. 2014. № 4 (81). С. 6-17.

18. Власова А.В. Структура субъективного гражданского права : дис. ... канд. юрид. наук. Ярославль, 1998. 150 с. ; Крашенинников Е.А. К теории права на иск. Ярославль, 1995. 76 с. ; Его же. Основное разделение гражданских прав // Материалы Всероссийской научной конференции, посвященной 200-летию Ярославского государственного университета им. П.Г. Демидова. Ярославль, 2003. С. 3-5 ; Его же. Регулятивные и охранительные субъективные гражданские права // Очерки по торговому праву : сборник научных трудов. Вып. 14 / под ред. Е.А. Крашенинникова. Ярославль, 2007. С. 5-16.

19. Мотовиловкер Е.Я. Основное разделение охранительных правоотношений // Вопросы теории охранительных правоотношений. Ярославль, 1991. С. 25-27.

20. Там же. С. 26.

21. Мотовиловкер Е.Я. Теория регулятивного и охранительного права. Воронеж, 1990. 135 с.

22. Мотовиловкер Е.Я. Основное разделение ... С. 26-27.

23. Мотовиловкер Е.Я. Теория ... С. 125.

24. Мильков А.В. Правовое регулирование защиты гражданских прав и правовых интересов : дис. ... д-ра юрид. наук. M., 2015. 442 c.

25. Кархалев Д.Н. Указ. соч. С. 43-48. 
26. Определяя значение этой классификации, автор делает следующий вывод: «...охранительные правоотношения могут возникать при нарушении любых гражданских прав, во всех институтах гражданского права» (Кархалев Д.Н. Указ. соч. С. 43). Между тем это положение является общеизвестным и широко признанным, в связи с чем данная классификация ничего не добавляет к пониманию особенностей охранительных гражданских правоотношений.

27. Характеризуя эту классификацию, Д.Н. Кархалев указывает: «В данной классификации подчеркивается особенность возникновения охранительного правоотношения, которая заключается в том, что оно может возникать не только при нарушении субъективного права, но и при создании угрозы его нарушения» (Указ. соч. С. 43). По поводу этого разделения скажем, что оно имело бы смысл, если бы автор сумел показать отличие охранительных гражданских правоотношений, возникающих при нарушении субъективного права, от охранительных гражданских правоотношений, возникающих при угрозе его нарушения. Однако исследователь этого не делает, как представляется, по той причине, что таких отличий не имеется.

28. Об этой классификации автор пишет: «Значение данной классификации состоит в том, что в большинстве случаев восстановление правового положения в охранительном обязательстве осуществляется в имущественной форме» (Кархалев Д.Н. Указ. соч. С. 44). К данному пункту можно выдвинуть те же претензии, что и к предыдущему: классифркация не показывает различий выделенных исследователем видов охранительных гражданских правоотношений и не продвигает нас по пути уяснения их сущности.

29. С целесообразностью данной классификации, пожалуй, можно было бы согласиться, если бы специальная глава работы, в которой выделенные в этой классификации виды рассматриваются подробно, не изобиловала бы фрактическими ошибками и необоснованными теоретическими положениями (Кархалев Д.Н. Указ. соч. С. 178-328). Поскольку критика этих ошибок требует самостоятельного анализа, в настоящей работе мы на ней не останавливаемся.

30. Описывая достоинства этой классификации, автор отмечает: «Данная классификация указывает на то, что охранительное правоотношение возникает не только при нарушении имущественных прав, возможно появление охранительной связи, вызванное нарушением неимущественных прав» (Кархалев Д.Н. Указ. соч. С. 44). По поводу этой классификации заметим, что она в несколько иной форме повторяет первую классификацию, соображения о значении которой нами уже высказаны.

31. Вряд ли избранный автором критерий классификации можно признать удачным, поскольку восстановление нарушенного права всегда осуществляется в натуральной форме (возврат вещи по виндикационному требованию, уплата денег при нарушении права требования по денежному обязательству). В противном случае это будет уже восстановление правового положения лица, т. е. удовлетворение охраняемого законом интереса лица в восстановлении его правового положения. Если принять данную классификацию, то правоотношение, в рамках которого лицо требует уплаты денег при нарушении права требования по денежному обязательству, должно быть отнесено к тем правоотношениям, в которых восстанавливается правовое положение субъекта, между тем речь идет о восстановлении нарушенного права, которое в данном случае только в такой форме и возможно.

32. Исходя из признанных в теории охранительного права положений, согласно которым: 1) обязанность существует в регулятивном правоотношении; 2) обязанное лицо, к которому направлено регулятивное право требования, имеет свободу выбора и, следовательно, принуждению в регулятивном правоотношении не находится места; 3) принудительность является свойством охранительного правоотношения; 4) возникновение охранительного правоотношения свидетельствует о том, что к нарушителю применяется принуждение; 5) свобода выбора (добровольность) и принуждение несовместимы (см.: Бабаев А.Б., Белов В.А. Проблемы общего учения о гражданском правоотношении // Гражданское право: Актуальные проблемы теории и практики / под ред. В.А. Белова. М., 2007. С. $258-259$; Мильков А.В. Указ. соч. С. 9, 262, 311, 315, 325, 378 ; Мотовиловкер Е.Я. Теория ... С. 53-56, 74-80, 124-125), полагаем, что данное отстаиваемое автором деление охранительных гражданских правоотношений ошибочно.

33. В качестве цели рассматриваемого правоотношения автор называет восстановление субъективного права или правового положения. Полагаем, что ситуации, в которых охранительные правоотношения прекращаются вследствие невозможности их реализации, вполне могут иметь место, например если после удовлетворения виндикационного иска должник уничтожит вещь. Однако в данном случае уничтожение повлечет возникновение нового охранительного правоотношения по восстановлению нарушенного правового положения субъекта. Характеризуя практическое значение данной классификации и указывая, что право может быть не восстановлено при наличии правопрекращающих юридических фрактов, Д.Н. Кархалев пишет: «В этом случае нет необходимости применять меры принуждения, поэтому суды должны учитывать данное свойство охранительной связи» (Указ. соч. С. 45). Между тем хорошо известно, что в случае невозможности восстановления права субъект обращается с требованием о защите своего охраняемого законом интереса в восстановлении нарушенного правового положения. Возникшее при этом охранительное правоотношение также реализуется на основе принуждения. Поэтому мы должны заключить, что вывод автора о практическом значении этой классификации является неверным.

34. В качестве последних исследователь называет законных представителей, отвечающих за малолетних. При этом он указывает, что «данная классификация имеет практическое значение, поскольку возложение мер принуждения иногда допускается в отношении лиц, не нарушавших право» (Кархалев Д.Н. Указ. соч. С. 45). Заметим, что применение мер принуждения в отношении лиц, не нарушавших право, по общему правилу не допускается, а законный представитель, отвечающий за малолетнего, является стороной охранительного правоотношения, следовательно, его нельзя характеризовать как «лицо, не нарушавшее право».

35. Классификации № 10-13 мы оцениваем как надуманные.

36. Единственная классификация, которая в определенной мере отражает сущность охранительного гражданского правоотношения.

37. Кожара В.Л. Классификационное движение ... С. 14

38. Кожара В.Л. Классификационное движение ... ; Новые идеи ... ; Розова С.С. Указ. соч. ; Степкина М.В. Гносеологический статус классификации как формы познания : дис. ... канд. филос. наук. Самара, 2006. 159 с. ; Субботин А.Л. Классификация. М., 2001. 94 с.

\section{References:}

Babaev, AB \& Belov, VA (ed.) 2007, 'Problems of the general doctrine of civil legal relationship', Grazhdanskoye pravo: Aktual'nyye problemy teorii i praktiki, Moscow, pp. 258-259, (in Russian).

Chekhovskaya, T 1984, 'It is chaos without it', Knigi, otkryvayushchiye mir, Moscow, pp. 93, 94, (in Russian).

Corbin, A 1921, 'Jural Relations and Their Classification', Faculty Scholarship Series, Paper 2873, viewed 05 December 2017, <http://digitalcommons.law.yale.edu/cgi/viewcontent.cgi?article=3877\&context=fss_papers>. 
Isakov, VB 1980, Set of facts in the mechanism of legal regulation, Saratov, 128 p., (in Russian).

Ivanov, AA 2014, 'The problem of classifying the legal responsibility (case study of responsibility in the field of environmental protection)', Vestnik Volzhskogo universiteta im. V.N. Tatishcheva, no. 4 (81), pp. 6-17, (in Russian).

Ivin, AA 2008, Logic, manual, Moscow, 336 p., (in Russian).

Karhalev, DN 2009, Protective civil legal relationship, Moscow, 332 p., (in Russian).

Kedrov, BM 1961, Classification of sciences, in 3 books, book I, Moscow, 472 p., (in Russian).

Kozhara, VL 2006, Classification movement, Borok, 40 p., (in Russian).

Kozhara, VL 2008, 'Phenomenon of natural classification', Novyye idei v nauchnoy klassifikatsii: sbornik nauchnykh trudov, iss. 5, Yekaterinburg, pp. 117-143, (in Russian).

Krasheninnikov, EA 1995, Concerning the theory of the right to claim, Yaroslavl, 76 p., (in Russian).

Krasheninnikov, EA 2003, 'The main division of civil rights', Materialy Vserossiyskoy nauchnoy konferentsii, posvyashchennoy 200-letiyu Yaroslavskogo gosudarstvennogo universiteta im. P.G. Demidova, Yaroslavl, pp. 3-5, (in Russian).

Krasheninnikov, EA 2007, 'Regulative and protective subjective civil rights', Ocherki po torgovomu pravu: sbornik nauchnykh trudov, Yaroslavl, pp. 5-16, (in Russian). sian).

Meyen, SV \& Shreider, YuA 1976, 'Methodological aspects of classification theory', Voprosy filosofii, no. 12, pp. 67-79, (in Rus-

Motovilovker, EYa 1990, Theory of regulatory and protective law, Voronezh, 135 p., (in Russian).

Motovilovker, EYa 1991, 'The main division of protective legal relations', Voprosy teorii okhranitel'nykh pravootnosheniy, Yaroslavl, pp. 25-27, (in Russian).

Milkov, AV 2015, Legal regulation of the protection of civil rights and legal interests, D.Phil. thesis, 442 p., (in Russian).

Orekhov, IV 2016, 'Problems of classifying sub-institutions of law', Pravo. Zhurnal Vysshey shkoly ekonomiki, no. 1, pp. 37-47, (in Russian).

Pokrovsky, MP 2013, 'The functions of classification', Yezhegodnik-2012: trudy IGG UrO RAN, iss. 160, Yekaterinburg, pp. 344352, (in Russian).

Rozova, SS 1986, Classification problem in modern science, Novosibirsk, 223 p., (in Russian).

Stepkina, MV 2006, Gnoseological status of classification as a form of cognition, PhD thesis, Samara, 159 p., (in Russian).

Subbotin, AL 2001, Classification, Moscow, 94 p., (in Russian).

Vlasova, AV 1998, Structure of subjective civil law, PhD thesis, Yaroslavl, 150 p., (in Russian). 